\title{
PRODUÇÃO DO PARASITÓIDE COTESIA FLAVIPES (HYMENOPTERA: BRACONIDAE) PARA CONTROLE BIOLÓGICO DA BROCA DA CANA-DE-AÇÚCAR (DIATRAEA SACCHARALIS) (LEPIDOPTERA: CRAMBIDAE)
}

DINIZ, Fabiana Ruscitti ${ }^{1}$

RODRIGUES, Karoline Fernandes ${ }^{1}$

ROSSI, Marta Maria

Recebido em: 2008-06-06

Aprovado em: 2008-06-16

ISSUE DOI: $10.3738 / 1982.2278 .86$

RESUMO: Desde a introdução do parasitóide larval Cotesia flavipes no Brasil em 1971, pesquisas foram desenvolvidas para se obter os melhores métodos de criação massal, em laboratório, visando ao controle da praga mais importante da cultura da cana de açúcar, a broca da cana-de-açúcar (Diatraea saccharalis). Compilaram-se, neste trabalho, os atuais métodos de produção massal de Cotesia flavipes, bem como, as salas necessárias em um laboratório de controle biológico, com os ambientes favoráveis para criação e manutenção do hospedeiro (Diatraea saccharalis) e do parasitóide (Cotesia flavipes), durante todo o ano. Discutiu-se ainda a necessidade do controle de qualidade dentro da criação massal de insetos benéficos, sendo a contaminação por patógenos um dos maiores obstáculos para se conseguir um produto de qualidade e que tenha desempenho desejável no campo.

Palavras chave: Laboratório de Controle biológico. Produção massal. Inimigo natural.

\section{PRODUCTION OF PARASITOID Cotesia flavipes (HYMENOPTERA: BRACONIDAE) FOR BIOLOGICAL CONTROL OF SUGARCANE BORER (Diatraea saccharalis) (LEPIDOPTERA: CRAMBIDAE)}

SUMMARY: Since the introduction of Cotesia flavipes (larval parasitoid) in Brazil, in 1971, researches has been developed to obtain the best laboratorial methods of massal rearing, aiming the most important plague control in sugarcane, the sugarcane borer Diatraea saccharalis. The actual methods of massal rearing of Cotesia flavipes were verified in this work, as well as the rooms needed in a biological control laboratory, with the propitious environment to rear and maintain host (Diatraea saccharalis) and parasitoid (Cotesia flavipes) during all the year. This work also discuss the necessity of a quality control in the beneficial insects massal rearing, as the pathogen contamination is one of the highest obstacle to get a quality product with desirable performance in field.

Keywords: Biological control Laboratory. Massal production. Natural ennemies.

1 Engenheiras Agrônomas, UFG/Goiânia - GO

2 Professora Doutora da Faculdade de Agronomia "Dr. Francisco Maeda" FAFRAM - Ituverava - SP e do Centro Universitário Moura Lacerda - Ribeirão Preto - SP 


\section{INTRODUÇÃO}

Controle biológico é um processo natural de regulação populacional de insetos através de inimigos naturais, os quais se constituem nos agentes de mortalidade biótica. A utilização desses inimigos naturais propiciou o surgimento do "controle biológico aplicado", que se trata de liberações inundativas de parasitóides ou predadores após a sua produção massal em laboratório, com objetivo de reduzir, rapidamente, a população da praga para seu nível de equilíbrio (PARRA et al, 2002).

No Brasil, a introdução de inimigos naturais foi iniciada em 1921, com a importação de Prospaltela berlesi Howard (Hymenoptera: Aphelinidae), proveniente dos EUA, para o controle de cochonilha-branca-do-pessegueiro, Pseudaulacaspis pentagona (Targ-Tozz) (Hemíptera: Diaspidae) (PARRA et al, 2002), mas, nos últimos anos, que se registraram grandes avanços nesta área, em nosso país.

O sucesso do controle biológico depende de um completo entendimento sobre os organismos envolvidos, tanto pragas como inimigos naturais, sendo que a criação destes insetos, em laboratório, torna-se uma ferramenta importante para que um programa visando ao uso destes agentes seja satisfatório.

Um dos casos de controle biológico mais conhecido no Brasil é o do controle da broca da cana-de-açúcar Diatraea saccharalis (Lepidoptera: Crambidae) por Cotesia flavipes (Hymenoptera: Braconide). Após a introdução e liberação da C. flavipes, a intensidade de infestação da broca-da-cana, que chegou a 8, a 10\%, em 1979-1980, passou para 2,4\%, em 1999 no Estado de São Paulo (BOTELHO; MACEDO, 2002). Os resultados da pesquisa demonstram que o controle biológico de D. saccharalis, por meio da liberação de C. flavipes, é um sucesso com real contribuição na redução da intensidade de infestação da praga.

A vespinha Cotesia flavipes foi introduzida pela primeira vez no Estado de São Paulo, em 1971, sem sucesso (PINTO, 2006), e somente em 1978, houve o aperfeiçoamento na tecnologia, o que tornou sua produção em laboratório mais simples.

Esta revisão tem como objetivo evidenciar as etapas de produção da $C$. flavipes e os avanços nas suas técnicas de criação, para uso em controle biológico.

\section{REVISÃO DA LITERATURA}

O bom desempenho do agente de controle biológico, no campo, depende de variáveis ambientais, climáticas e da qualidade do próprio agente, entendida como a sua capacidade de localizar e parasitar o hospedeiro. No caso da Cotesia flavipes, a qualidade depende de uma série de cuidados durante o processo de produção, desde a obtenção do hospedeiro até o acondicionamento do agente para o campo e sua liberação (MACEDO, 2002).

A criação da vespa $C$. flavipes deve ser feita em laboratórios projetados para a produção 
de grandes quantidades desse agente (produção massal), além da criação da broca da cana-deaçúcar, por ser o hospedeiro para esse parasitóide. Essa criação envolve diferentes tecnologias que utilizam dietas naturais e artificiais e condições de ambiente controladas (CANO et al, 2006).

O laboratório é a base física e técnica de produção do parasitóide e, para isso, deve possuir equipamentos, pessoal e dimensionamento adequado. Suas principais salas e suas respectivas funções são descritas a seguir.

\section{a) SALA DE POSTURA}

É o local onde são mantidas câmaras com adultos de $D$. saccharalis para obtenção de ovos. O laboratório deve ter um planejamento de liberação de C. flavipes/mês, e, seguindo essa meta, fazer a programação semanal de montagem de câmaras para postura no laboratório. A sala deve ter ambiente propício para acasalamento e postura, com temperatura noturna de 20 a $22^{\circ}$ $\mathrm{C}$, com período escuro totalmente sem luz e temperatura diurna de 26 a $28^{\circ} \mathrm{C}$, mantida com ar condicionado e fotofase de 12 a 14 horas (MACEDO, 2002).

As câmaras são tubos de PVC de, aproximadamente, seis polegadas e $20 \mathrm{~cm}$ de altura, revestidos com papel sulfite umedecido com água destilada, onde, segundo Cano et al. (2006), devem ser colocados 40 casais da mariposa por unidade. Para Macedo (2002), cada câmara deve conter 30 fêmeas e 45 machos, e, diariamente, devem-se eliminar os indivíduos mortos e, nunca colocar novos adultos em câmaras velhas para completar o número deles. De acordo com Parra et al. (1999), a broca da cana-de-açúcar não necessita de carboidratos na sua alimentação, já que insetos, alimentados apenas com água, colocam número de ovos iguais ou superiores. Essencial é a presença de ambiente úmido, pois, em comparação ao ambiente seco, ocorre maior postura. No ambiente seco, não há eclosão, e a longevidade e o tamanho das posturas são drasticamente reduzidos.

Diariamente, as folhas de sulfite, contendo as posturas, são retiradas, desinfetadas e mantidas em sala climatizada à temperatura de $20^{\circ} \mathrm{C}$ (CANO et al, 2006). A desinfecção poderá ser feita através de duas técnicas: uso de solução de hipoclorito de sódio, em uma concentração de $0,05 \%$, passando, em seguida, pela solução de sulfato de cobre a $17 \%$ ou, uso de solução de formol, a 0,5\%, passando, em seguida, pela solução de sulfato de cobre, a 17\%. Estudos realizados por De Pietro (2006) evidenciaram que a desinfecção dos ovos da broca-da-cana com a solução de formol, a 0,4\%, melhorou as características biológicas da vespinha C. flavipes, criada em lagartas desse hospedeiro infectadas por protozoário. Porém, para Ramos (2006), a desinfecção de ovos de $D$. saccharalis com solução de hipoclorito de sódio a $0,05 \%$ melhora a qualidade da criação do hospedeiro, quando este apresenta sinais de infecção por protozoários.

As folhas de papel desinfetadas são colocadas para secar, acondicionadas em potes plásticos, envolvidas por papel alumínio, para conservar a umidade dos ovos. Estes potes deverão ser mantidos em temperatura de $20 \pm 1^{\circ} \mathrm{C}$. 
O período de incubação dos ovos e a porcentagem de eclosão variam com a temperatura. De acordo com estudos realizados por Melo e Parra (1988), o período de incubação decresce com o aumento da temperatura, enquanto a porcentagem de eclosão é bastante variável, obtendose o maior valor a $30^{\circ} \mathrm{C}$.

Para a criação de adultos, Melo e Parra (1988) evidenciaram que a temperatura de $20^{\circ} \mathrm{C}$ é a mais adequada, porque, nessa condição, obtém-se maior número de ovos por fêmea, maior período de oviposição e maior longevidade de machos e fêmeas. Quando as temperaturas são muito altas, ocorre um ressecamento mais rápido do papel da câmara de acasalamento, criando um ambiente com condições adversas e diminuindo, assim, a longevidade dos insetos. Além disso, na temperatura de $32^{\circ} \mathrm{C}$, ocorre uma grande porcentagem de adultos deformados, porque temperaturas elevadas afetam a disponibilidade de ácidos graxos na fase pupal, provocando deformações nas asas deste lepidóptero.

\section{b) SALA DE DIETA}

É considerada uma das mais importantes salas do laboratório, pois é o local onde são preparadas as dietas artificiais, utilizadas na criação de lagartas de D. saccharalis. O local deve ser mantido limpo, evitando entrada de pessoas estranhas durante o preparo das dietas. Por se tratar de uma sala fechada, utilizam-se ar condicionado e exaustor para manter a temperatura de $25^{\circ} \mathrm{C}$ e iluminação natural (BOTELHO; MACEDO, 2002).

Para a produção de lagartas há utilização de um frasco especial de $500 \mathrm{ml}$, vidro transparente, tampa composta de anel plástico com rosca e tela metálica. Esse material tem sido utilizado, trazendo economia de mão-de-obra, insumos e vasilhame. O frasco, antes da colocação da dieta, deve ser esterilizado corretamente, para receber $200 \mathrm{ml}$ de dieta ainda quente para se solidificar na posição horizontal. (MACEDO, 2002). Após aproximadamente cinco dias da desinfecção das posturas, as larvas estão prestes a eclodir. Elas são vistoriadas, e as melhores são selecionadas (CANO et al, 2006). O papel contendo os ovos é recortado, e são colocados cerca de 250 ovos/frasco, utilizando o ambiente interno devidamente esterilizado das câmeras de infestação (MACEDO, 2002). Caso seja feita a opção por frascos menores, usa-se um tubo de vidro com apenas 30 ovos/frasco (CANO et al, 2006)

A dieta utilizada pelos laboratórios é a de Hensley e Hammond (1968), modificada para a criação das lagartas e descritas em Cano et al, 2006. Duas dietas são utilizadas: a de "criação", adotada no início da alimentação da lagarta até a seleção para inoculação ou obtenção de pupas; e a dieta de "realimentação", que é utilizada para as lagartas inoculadas ou para as que continuam o ciclo para se transformarem em pupa (MACEDO, 2002). Os ingredientes das duas dietas são iguais, sendo modificados, apenas, nas quantidades. Já a dieta de realimentação apresenta-se mais nutritiva e de maior consistência, para ser cortada em cubos e colocada em caixas plásticas para a realimentação das lagartas. 


\section{c) SALA DE DESENVOLVIMENTO}

É o local onde são acondicionados os frascos com ovos de D. saccharalis para manter o desenvolvimento das lagartas. A temperatura deve ser mantida a $28^{\circ} \mathrm{C}$, com auxilio de ar condicionado, aquecedor e luminosidade natural sem incidência de raios solares (MACEDO, 2002).

Segundo Melo e Parra (1988), a viabilidade larval é maior a $30^{\circ} \mathrm{C}$ e atinge o menor valor a $32^{\circ} \mathrm{C}$, o que pode ser influenciado pelo rápido ressecamento da dieta nessa temperatura. Além disso, pode ocorrer condensação nas paredes dos tubos da criação, o que provoca alta mortalidade das lagartas de primeiro instar por afogamento. Para que isso não ocorra, as lagartas de primeiro e segundo instar exigem umidade abaixo de $85 \%$ e, somente a partir do terceiro instar, a umidade pode chegar a 90\% sem afetar o desenvolvimento. Na temperatura de $32^{\circ} \mathrm{C}$, a oxidação da dieta é mais rápida, o que leva à morte lagartas de primeiro instar. $\mathrm{O}$ número de ecdises de $D$. saccharalis também é influenciado pela temperatura. De 20 a $22^{\circ} \mathrm{C}$, as lagartas apresentam seis instares, sendo o intervalo entre eles de maior duração, enquanto, a $25^{\circ} \mathrm{C}, 30^{\circ}$ $\mathrm{C}$ e $32^{\circ} \mathrm{C}$, as lagartas apresentam cinco ou seis instares, com predomínio de lagartas de seis instares.

Em laboratórios em que não é possível o controle de temperatura, trabalho produzido por Parra et al. (1983) sugerem que, durante o período mais frio do ano, as lagartas fiquem em ambiente com 24 horas de luz, sendo o período larval reduzido, obtendo lagartas de boa viabilidade, independentemente da qualidade do adulto produzido. Durante o período mais quente do ano, deve-se optar pelo fotoperíodo de 12 horas, verificando uma maior viabilidade das lagartas, sendo possível obter uma geração a mais de insetos no decorrer do ano.

As lagartas recém-eclodidas começam a se alimentar da dieta artificial e penetram no interior destas (CANO etal,2006). Deve-se fazer um acompanhamento diário do desenvolvimento das lagartas, para evitar eventuais frascos contaminados, até atingirem o ponto de "aptas" para inoculação, em média 14 a 15 dias (MACEDO, 2002).

\section{d) SALA DE INOCULAÇÃO}

É o ambiente onde se realizam as "inoculações" da lagarta pelo parasitóide C. flavipes. O local deve possuir excelente luminosidade e temperatura de $28 \pm 2^{\circ} \mathrm{C}$, mantida através de aquecedor e circulador de ar (MACEDO, 2002).

Os frascos, contendo lagartas aptas ao parasitismo são levados para esta sala, onde são selecionadas as lagartas de tamanho entre 15 a $23 \mathrm{~mm}$ e descartadas aquelas pequenas, com baixa mobilidade e coloração anormal. Para manutenção do laboratório e continuação do ciclo do hospedeiro, $5 \%$ das lagartas são realimentadas com cubos da dieta de realimentação em caixas plásticas e agrupadas em 4 ou 5, para obtenção de pupas

As lagartas selecionadas para o parasitismo, 95\%, são oferecidas, individualmente, para 
o adulto fêmea da $C$. flavipes, para que ocorra a inoculação e postura de ovos no interior do corpo da lagarta. Segundo Rossi (2000), as chances de sobrevivência das larvas de C. flavipes diminuem com o aumento do grau do superparasitismo de $D$. saccharalis, quando as oviposições são executadas por diferentes fêmeas. A fêmea de $C$. flavipes é reconhecida pelas antenas, que são menores quando comparadas às do macho.

As lagartas inoculadas são colocadas em número de 4 a 5 em caixa plástica, contendo um cubo de dieta de realimentação (CANO et al, 2006). Em seguida, as caixas com lagartas, inoculadas e não inoculadas, são acondicionadas em salas climatizadas chamadas de sala de lagartas "inoculadas".

\section{e) SALA DE LAGARTAS "INOCULADAS"}

É o local onde são acondicionadas as caixas plásticas com lagartas parasitadas e as lagartas realimentadas, para se transformarem em pupas (MACEDO, 2002). Também serve de local para copos plásticos com massas de $C$. flavipes até sua emergência e para as "gaiolas" de nascimento, contendo pupas de $D$. saccharalis até sua emergência.

As crisálidas de D. saccharalis, destinadas à continuação da produção do laboratório, são selecionadas, retirando-se as deformadas ou com anomalia, e agrupadas em caixa plástica, também chamada de gaiola, para nascimento (CANO et al, 2006), com tampa telada por papel sulfite umedecido. Diariamente, os adultos, após a emergência, são novamente selecionados e separados por sexo, através da coloração das asas e tamanho. As fêmeas são maiores, com abdome volumoso e asas brancas, enquanto o macho possui asas mais pigmentadas. Em seguida, os insetos escolhidos são levados para a sala de postura onde são colocados nas câmaras de acasalamento para oviposição.

A temperatura desta sala deve ser mantida a $28^{\circ} \mathrm{C}$, com auxilio de ar condicionado, aquecedor e luminosidade natural, mas sem incidência de raios solares (MACEDO, 2002).

Segundo Parra et al. (1983), o fotoperíodo ideal para obtenção de pupas viáveis, sem deformação dos adultos, é de 12 horas. Nesse trabalho, observou-se que lagartas submetidas a 24 horas de luz resultam em pupas de menos peso e com maior índice de deformação dos adultos, independentemente de ser a época mais fria ou quente do ano, já que o ambiente no trabalho não tinha temperatura controlada.

Em trabalho realizado por Melo e Parra (1988), foi avaliada a influência de diferentes temperaturas na fase de pupa. Constatou-se que, no intervalo de 20 a $30^{\circ} \mathrm{C}$, as pupas fêmeas sempre foram mais pesadas do que os machos e que, na temperatura de $32^{\circ} \mathrm{C}$, tanto os machos como as fêmeas apresentaram menos peso, indicando que temperaturas acima de $30^{\circ} \mathrm{C}$ influenciam no desenvolvimento. 


\section{f) SALA DE REVISÃO}

A temperatura, nesta sala, deve ser mantida em $28^{\circ} \mathrm{C}$, com auxílio de circulador de ar; ela deve ter boa luminosidade, mas sem incidência de raios solares. Depois de 13 a 20 dias, são revisados os lotes de lagartas inoculadas, buscando as "massas" dos parasitóides ou pupas da praga (MACEDO, 2002). Esse procedimento é repetido mais uma vez, sete dias após a primeira revisão (CANO et al, 2006). A massa do parasitóide é, na verdade, a pupa da lagarta protegida por um casulo construído pela larva com fios de seda, sendo estes indivíduos sempre provenientes de um mesmo hospedeiro (BOTELHO; MACEDO, 2002).

É adequado manter as massas de $C$. flavipes com a mesma cor no mesmo copo, pois o material de cor preta tem a emergência de adultos mais cedo do que o material de cor branca. Assim, se houver mistura de massas, não haverá uniformidade de eclosão e nem de acasalamento. As "massas" de C. flavipes, destinadas à manutenção do parasitóide em laboratório, são acondicionadas em número de dez em caixinhas plásticas, observando-se o período de emergência dos adultos. Após a emergência, os adultos são mantidos por aproximadamente 12 horas nos recipientes, para que possam acasalar, estando prontos para o parasitismo de novas lagartas, após esse procedimento. As vespinhas, destinadas à liberação no campo, são acondicionadas em copos biodegradáveis ou copos plásticos com, no mínimo, 1.500 adultos em cada um.

\section{g) ALMOXARIFADO}

É o local onde os componentes da dieta, material de limpeza e o material empregado na criação, são armazenados enquanto não estão sendo utilizados (MACEDO, 2002).

\section{h) ÁREA DE LIMPEZA}

É local destinado ao abrigo das máquinas de lavar caixas plásticas, tubos ou frascos e dos tanques com água e desinfetante. Também serve de depósito para o material a ser lavado ou já limpo, empregado no dia-a-dia da produção (MACEDO, 2002).

Esses cuidados são muito importantes para evitar a contaminação por fungos e bactérias, e, assim, se consigam altos níveis de hospedeiros e parasitóides. Os laboratórios devem ser mantidos sempre limpos, desinfetando o piso e as mesas com solução de hipoclorito de sódio a $0,2 \%$. No caso de contaminação, a atenção com a assepsia deve ser redobrada e a desinfecção da sala de dieta deve ser completada durante a noite (CANO et al, 2006).

\section{CONTROLE DE QUALIDADE}

Somente na década de 80, o controle de qualidade em criações massais de insetos 
benéficos passou a ser mencionado, e, um pouco mais tarde, o tópico se tornou popular. $\mathrm{O}$ grupo de trabalho sobre "controle de qualidade de artrópodes criados massalmente" iniciou a discussão entre produtores de inimigos naturais e cientistas sobre o ponto de vista comercial, gerando uma série de workshops sobre o assunto, resultando em diretrizes sobre o controle de qualidade. Até o momento, as diretrizes compreendem características relativamente fáceis de serem determinadas num laboratório (ex: emergência, razão sexual, longevidade, fecundidade, tamanho do adulto e taxa de predação/parasitismo) (VAN LENTEREN, 2002).

O controle de qualidade é justificado por Leppla e Ashley (1989) como o monitoramento e controle sofisticado do complexo processo de produção para programas de criação massal que assegurem que o produto apresente qualidade razoavelmente consistente e alcance o desempenho desejado no campo. O objetivo das liberações de inimigos naturais, criados massalmente, é o controle da praga. Assim, o objetivo do controle de qualidade deve ser determinar se o inimigo natural está ainda em condições de controlar a praga eficientemente. Desta forma, o interessante não é determinar a qualidade ótima, e sim, a qualidade aceitável (VAN LENTEREN, 2002).

Os produtores de inimigos naturais criam, principalmente, predadores e parasitóides. Métodos de criação massal desenvolvidos de forma improvisada, podem resultar em inimigos naturais de má qualidade. Se o sucesso for desejado, o controle de qualidade do produto final é essencial. Os desenvolvimentos na área de produção massal: controle de qualidade, armazenamento, envio e liberação de inimigos naturais têm reduzido os custos de produção e levado a uma qualidade melhor do produto, mas muito mais poderá ser feito, demonstrando que programa de qualidade é uma necessidade (VAN LENTEREN, 2002). Sendo assim, Botelho e Macedo (2002) consideram que é imprescindível que, no caso de C. flavipes, critérios sejam definidos para garantir a qualidade do produto, desde a fundação das colônias em laboratório, até sua utilização final.

Um dos maiores obstáculos encontrados no controle de qualidade é o alto nível de contaminação por patógenos. Para contornar este problema, a desinfecção dos insetos e dos ingredientes empregados na dieta é de extrema importância (VAN LENTEREN, 2002).

\section{CONSIDERAÇÕES FINAIS}

Cada vez mais, a legislação de proteção ambiental tende a excluir a operação de queima prévia do canavial, reduzindo, gradualmente, as áreas em que essa prática ocorre. Dessa forma, com o uso da colheita mecanizada de cana crua, o controle biológico será cada vez mais importante como método de controle da lagarta da broca da cana-de-açúcar, e o insumo biológico (parasitóide) deverá ser produzido em larga escala e estar disponível no mercado, para que possa ser usado assim que a praga atingir seu nível de controle. Assim, o aprimoramento das técnicas de criação desse inimigo natural e o incremento de seu uso nas áreas de expansão de canaviais tornam-se imprescindíveis para que possamos proteger o meio ambiente e garantir a sustentabilidade de nossa agricultura. 


\section{REFERÊNCIAS}

BOTELHO, P. S; MACEDO, N. Cotesia flavipes para o controle de Diatraea saccharalis. In: PARRA, J. R. P. et al. Controle biológico no Brasil: parasitóides e predadores. São Paulo: Manole, 2002. p. 409-425.

CANO, M. A. V; SANTOS, E. M. dos; PINTO, A. de S. Produção de cotesia flavipes para controle da broca-da-cana. In: PINTO, A. de S. Controle de pragas da cana de açúcar. Sertãozinho: Biocontrol, 2006. p. 21-24.

De PIETRO, J. de. Efeito da dieta, da desinfecção de ovos e da população de Diatraea saccharalis (Lepidoptera: Crambidae), infectada por protozoário ou sadia, na criação massal de Cotesia flavipes (Hymenoptera: Braconidae). 2006. 43p. Trabalho de Conclusão de Curso (Graduação em Agronomia). Centro Universitário Moura Lacerda, Ribeirão Preto.

HENSLEY, S. D; HAMMOND, A. M. Laboratory techniques for rearing the sugar cane borer on an artificial diet. J. Econ. Entomol., n.61, p. 1742-1743. 1968.

LEPPLA, N. C; ASHLEY, T. R. Quality control in insect mass production: a review and model. Bulletin of the Entomological Society of America, n. 4, p. 33- 44, 1989.

MACEDO, N. Método de criação do parasitóide Cotesia flavipes (Cameron, 1891). In: BUENO, V. H. P. (Ed.). Controle biológico de pragas: produção massal e controle de qualidade. Lavras: UFLA, 2002. p. 161-175

MELO, A. B. P. de; PARRA, J. R. P. Biologia de Diatraea saccharalis em diferentes temperaturas. Pesquisa Agropecuária Brasileira, Brasília, v. 23, n. 7, p.663-680, jul. 1988.

PARRA, J. R. P. et al. Controle Biológico: terminologia. In: PARRA. et, al. (Eds.) Controle biológico no Brasil: parasitóides e predadores. São Paulo: Manole, 2002, p. 1-16.

PARRA, J. R. P. et al. Efeito do fotoperíodo no ciclo biológico de Diatraea saccharalis. Pesquisa Agropecuária Brasileira, Brasília, v. 18, n. 5, p.463-472, mai. 1983.

PARRA, J. R. P. et al. Efeito da nutrição de adultos e da umidade na fecundidade de Diatraea saccharalis. Sociedade Entomológica do Brasil, Londrina, v. 28, n. 5, mar. 1999.

PINTO, A. de S. O controle biológico de pragas da cana-de-açúcar. In: PINTO, A. de S. Controle de pragas da cana de açúcar. Sertãozinho: Biocontrol, 2006. p. 9-13. 
RAMOS, C. A. Efeito da dieta e da desinfecção de ovos na criação massal de Diatraea saccharalis (Lepidoptera: Crambidae), infectadas por protozoários ou sadias. 2006. 35p. Trabalho de Conclusão de Curso (Graduação em Agronomia). Centro Universitário Moura Lacerda, Ribeirão Preto.

ROSSI, M. N. Efeito do número de oviposições provenientes de diferentes fêmeas de Cotesia flavipes (CAM.) no número de descendentes que emergem de seu hospedeiro Diatraea saccharalis FABR. Naturalia, Rio Claro, São Paulo, n. 25, v. 25, p.271-280, 2000.

VAN LENTEREN, J. C. Controle de qualidade de agentes de controle biológico produzidos massalmente: conhecimento, desenvolvimento e diretrizes. In: BUENO, Vanda Helena Paes (Ed.). Controle biológico de pragas: produção massal e controle de qualidade. Lavras: UFLA, 2002. p. 21-45. 